\title{
The Role of Ultrasonographic Monitoring for Hip Joint Changes in Patients with Chronic Renal Failure
}

\author{
Damir Matoković, Miroslav Hašpl, Petar Petrić, \\ Sanja Škorvaga, Vlado Drkulec and Goran Šantak \\ Department of Orthopaedics, General County Hospital Pozega \\ Special Hospital for Orthopaedics and Traumatology of the Bone and Joint System \\ Akromion, Krapinske Toplice \\ Department of Internal Medicine, General County Hospital Pozega \\ Department of Clinical Biochemistry, General County Hospital Pozega \\ Department of Pediatrics, General County Hospital Pozega \\ Department of Surgery, General County Hospital Pozega
}

Croatia

\section{Introduction}

Chronic renal failure (CRF) is associated with life-threatening accumulation of metabolic products due to the inability of their elimination. On hemodialysis, toxic substances are eliminated from the site of their high concentration (blood) via semipermeable membrane to a lower concentration medium (dialysis fluid) by the principle of diffusion. Hemodialysis has been widely used since the end of the 1960s. Although hemodialysis significantly prolongs life expectancy in CRF patients, hemodialyzers cannot compensate for all kidney functions. Hemodialyzer function has been greatly upgraded by technical innovations, however, many kidney functions in the regulation of homeostasis such as hormone production, e.g., vitamin D active metabolite (calcitriol) and erythropoietin, and many other functions remain unfeasible. Kidneys are involved in mineral metabolism and are target organs for the action of parathormone. In CRF patients, bone metabolism impairment occurs at creatinine clearance of $50-60 \mathrm{~mL} / \mathrm{min}$. Therefore, prolonged duration of hemodialysis is associated with development of numerous complications, in particular those involving the osteoarticular system. These complications are due to osteodystrophy and dialysis related amyloidosis (DRA). Tenosinovitis, in particular involving finger and hand flexors, snapping fingers and joint contractures are frequently present, however, tendon rupture may also occur. Muscle atrophy leads to the loss of strength, inability to perform fine finger movements, with a reduced function and range of movements and joint contractures. The hands assume a typical shape of so-called amyloid hand, while fingers look like "guitar players" (Farrell \& Bastani, 1997; Fitzpatrick et al., 1996). Pain, swelling, degenerative joint changes and effusions are bilateral and symmetric, and may vary from very mild through severe where movements are painful and limited (Kelly et al., 2007; Zhang et al., 2002). Shoulders, hips and knees are mostly involved, however, all other joints 
may also be affected (Yamamoto et al., 2008). Soft tissue and joint lesions lead to dysfunction of the musculoskeletal system. Subchondral cysts are seen on the bones and erosions on the joints; pathologic bone fractures may occur in advanced stages of amyloidosis. The number and size of the cysts increase with the length of dialysis. Amyloid bone cysts may frequently be misinterpreted as tumors. On x-ray study, amyloid cysts can be differentiated from "brown" tumors. Whereas the former are found in distal part of the bone, frequently bilateral, multiple, well delineated and with sclerotic edges, located subchondrally or in the area of ligament junction, "brown" tumors are found in the are of long bone diaphysis. 32 microglobulin is a polypeptide, molecular weight of 11800 daltons, found on the surface of most nucleated cells. Lymphocytes and T cells play a crucial role in the formation of $\beta 2-$ microglobulin. In normal individuals, $\beta 2$-microglobulin is found in tissue fluids, synovia, serum and urine, filtered via glomerular filtration, resorbed and degraded in proximal tubules. Reduced function of proximal tubules results in elevated $\beta 2$-microglobulin level in urine. Elevated serum $\beta 2$-microglobulin levels may be due to its enhanced synthesis, as in some inflammatory diseases (e.g., rheumatoid arthritis, systemic lupus erythematosus, Sjögren's syndrome, Crohn's disease, cytomegalovirus infection, infectious mononucleosis, hepatitis C, HIV infection, chronic osteomyelitis), or malignant and lymphoproliferative diseases (multiple myeloma, $\beta$-cell lymphoma, chronic lymphocytic leukemia), or because of its decreased secretion due to reduced glomerular filtration in CRF patients. A number of factors are responsible for elevated $\beta 2$-microglobulin level in the blood of hemodialysis patients. About 100-200 g $\beta 2$-microglobulin or 2-4 mg/kg body weight are synthesized per day, its reference plasma values ranging from 0.73 to $3.81 \mathrm{mg} / \mathrm{L}$ (Al-Taee et al., 2003; Farrell \& Bastani, 1997;). In CRF patients, there is no $\beta 2$-microglobulin elimination, thus its concentration being 15 to 60 fold normal values (Motomiya et al., 2001; Ohashi, 2001).

In human body, $\beta 2$-microglobulin is found in extracellular space, circulates as a free monomer and does not bind to plasma proteins (Connors et al., 1985). By polymerization, $\beta 2$-microglobulin is transformed from soluble to insoluble form and accumulated in the form of amyloid deposits in various tissues causing structural and functional organ lesions. The complications that develop due to amyloid accumulation involve visceral organs and osteoarticular system in particular. The visceral form of amyloidosis involves numerous organs, e.g., heart, lungs, gastrointestinal system and urogenital system; subcutaneous amyloid deposits are quite common, in particular those involving gluteal region, and may also be found intradermally around hair follicles, sebaceous glands and blood vessels (Jimenez et al., 1998). In amyloidosis involving osteoarticular system, amyloid is accumulated between cells (in the interstitium) but rarely in blood vessels, whereas in case of visceral complications in CRF patients, subendothelial amyloid accumulation is seen with deposits in vascular walls to produce intraluminal protrusions in blood vessels. In the second half of the 1970s, carpal tunnel syndrome was observed to occur in hemodialysis patients due to accumulation of a new amyloid type (Kenzora, 1978; Warren \& Otieno, 1975). In 1985, Geyo et al. demonstrated $\beta 2$-microglobulin to be responsible for the development of a new type of amyloidosis in CRF patients (Denesh \& Ho, 1998; Geyo et al., 1985; Tsvetkova et al., 2007). According to the World Health Organization 1993 nomenclature, amyloidosis in CRF patients is termed $A \beta 2 \mathrm{~m}$ amyloidosis. It is the most common complication in CRF patients. In the literature, a number of synonyms have been used for this type of amyloidosis, i.e. AB amyloidosis, dialysis amyloidosis, and dialysis related amyloidosis (DRA). As clinical manifestations of this complication occur in the advanced stage of the disease, it is necessary to detect it in 
its preclinical stage. Therefore, the lesions should be detected and followed-up before the clinical signs of the disease occur, and properly controlled during treatment. There are several diagnostic procedures used to follow-up the lesions involving osteoarticular system, e.g., x-ray, computed tomography (CT), magnetic resonance imaging (MRI), scintigraphy, biopsy, and ultrasonography (US). Changes of the osseous and articular structures are analyzed by use of x-ray studies. Radiological signs of arthropathy are present in patients undergoing hemodialysis for more than 5 years (Tsvetkova et al., 2007). X-ray is a presumptive method, i.e. bone lesions can be identified even before pain occurs. Changes are seen as typically distributed subchondral cystic bone lesions, usually of thin and sclerotic edges, joint erosions, and possibly pathologic fractures. After 10-year hemodialysis, $50 \%-60 \%$ of patients show bone cysts (Fitzpatrick et al., 1996). X-ray changes are not seen in early stages of the disease. Distribution and extension of amyloid pseudotumors and pseudocysts of bones and joints, around joints, small areas of osteolysis or cortical bone erosion are visualized by CT, however, this study is associated with exposure to higher irradiation doses (Kiss et al., 2005). MRI offers useful data on bone, joint and soft tissue changes and particular organ involvement (Fukuda \& Yamamoto, 2001; Kiss et al., 2005), however, MRI is a more expensive, less available and more time consuming method, and therefore less commonly employed in clinical routine. The usual noninvasive diagnostic studies include US, classic x-ray and MRI. However, these are nonspecific and low sensitivity studies. Scintigraphy is a specific noninvasive diagnostic method used to identify amyloidosis distribution and extension all over the body (Floege et al., 2001; Hawkins et al., 1990; Ketteler et al., 2001; Linke et al., 2000). Three scintigraphy methods are most widely employed: standard bone scintigraphy by use of Tc-diphosphonates; scintigraphy with iodine 123I labeled serum amyloid P component (SAP); and scintigraphy by use of specific protein precursors in $\mathrm{A} \beta 2 \mathrm{M}$ amyloid (131 $\mathrm{I}-\beta 2 \mathrm{~m})$. Biopsy is an invasive diagnostic method providing an insight into the local area lesions; however, it may be associated with periprocedural complications. Joint effusion puncture, rectal biopsy, abdominal adipose tissue biopsy (aspiration) and salivary gland biopsy are most commonly performed. Histologic changes of soft tissue develop far before clinical signs of the disease. Clinical signs of hemodialysis related amyloidosis occur in advanced stages of the disease. As clinical symptoms are nonspecific, they may easily be misinterpreted as other joint diseases. Patients undergoing hemodialysis for less than 5 years rarely show clinical signs of amyloidosis (Al-Taee et al., 2003). Carpal tunnel syndrome frequently occurs as the first clinical sign of amyloidosis (Ikegava et al., 1995; Shin et al., 2008). The number and severity of clinical symptoms are known to increase with the length of hemodialysis. After 15-year hemodialysis, clinical symptoms of hemodialysis related amyloidosis are present in $100 \%$ of patients (Al-Taee et al., 2003). Therefore, it is of utmost importance to follow-up the course of disease in its preclinical stage. There are direct and indirect diagnostic procedures used to demonstrate amyloidosis. An ideal diagnostic study should be noninvasive, repeatable, highly specific, inexpensive and widely available. Tissue biopsy is considered as the 'gold standard' to demonstrate amyloidosis, however, other diagnostic methods are also employed to reach the diagnosis. US has been widely accepted in the diagnosis of pathology, of the osteoarticular system soft tissues in particular. New US high-resolution devices with many technological innovations (e.g., offering the possibility of changing the frequency, focus, 3D image, using probes of various shape and size, movement analysis, i.e. real-time study, etc.) can measure morphological changes with precision of tenths of millimeter. 
Hemodialysis patients mostly show lesions of soft tissues, in particular tendons and synovial sheaths, with frequent tenosinovitis and joint effusion. On US, muscle lesions can be visualized, thickness of tendons, ligaments and joint sheaths measured, lesions of paraarticular structures observed, and extent of joint effusion followed-up; tissue vascularization can be followed-up by Doppler US. Although not highly specific, US is a presumptive, widely available, noninvasive, repeatable and inexpensive study free from ionizing radiation that can be used to follow-up the course of the disease, therapeutic effects and possible complications involving the osteoarticular system in CRF patients. US can be used as a control tool on therapy administration or puncture of joints, bursae, cysts, ganglia, or on tissue biopsy. The aim of the present study was to assess the impact of hemodialysis duration, patient age and $\beta 2$-microglobulin concentration at the onset of hemodialysis on morphological changes in the hip region.

\section{Patients and methods}

Bilateral hip US using a 7-cm linear probe of $7.5 \mathrm{MHz}$ was performed in 106 hemodialysis patients aged $>18$ to measure articular sheath thickness and articular effusion in both hips. During the procedure, the patient was in supine position, with the leg in neutral position. We used anterior longitudinal approach where the probe is parallel to femoral neck axis. Thickness of the hip joint sheath measured in the concave segment of the femur was determined as distance from the joint sheath inner to outer edge. Synovial effusion in the hip region was expressed as distance between anterior cortex of the femoral neck concave segment and inner edge of the hip joint sheath. A total of 424 US measurements were performed in the study group and 204 bilateral measurements in the control group. Control group consisted of 51 healthy subjects that underwent the same measurements of hip joint sheath thickness and articular effusion. Study patients were divided into three groups according to the length of hemodialysis ( $<36,36-72$ and $>72$ months) and age (18-50, 51-65 and $>65$ years). In study patients, serum $\beta 2$-microglobulin concentration was determined at the onset of hemodialysis, and in control subjects before US examination. All laboratory tests were performed at Laboratory of Biochemistry, Požega General Hospital, in Požega, Croatia. Beta2-microglobulin concentration was determined by use of the AxSYM $\beta 2-$ microglobulin microparticle enzyme immunoassay (MEIA; Abbott GmbH, Wiesbaden, Germany). Blood samples were obtained from cubital vein by use of Vacutainer system. Blood sample was centrifuged for $10 \mathrm{~min}$ at $3500 \mathrm{rpm}$ within 5 hours of venepuncture. Subjects with a history of previous injury or operative procedure on the study joints, inflammatory (chronic osteomyelitis, tuberculosis, HIV infection, hepatitis C), malignant or rheumatic diseases, systemic lupus erythematosus, sarcoidosis, Sjögren's syndrome, Crohn's disease, or lymphoproliferative diseases (multiple myeloma, $\beta$-cell lymphoma, chronic lymphocytic leukemia) were excluded. All study patients were undergoing hemodialysis with low-flux hemodialyzers. All examinations were performed by the author himself in order to prevent inter-examiner finding variability. All study subjects were informed on the study protocol, objectives and methods used, expected benefits, possible risks, etc. Inclusion in the study was voluntary and all subjects signed the informed consent form. Study protocol was approved by the Ethics Committees of the Požega General County Hospital, Dr. Josip Benčević General Hospital from Slavonski Brod, and School of Medicine, University of Zagreb from Zagreb, Croatia. 


\section{Statistical methods}

Kruskal-Wallis test was used to test significance of differences between different age groups. In addition, differences between pairs of groups were tested with Mann Whitney U-tests. Spearman's rank correlation coefficient was used to test correlation between age and concentration of $\beta 2 \mathrm{M}$. Data were presented as mean, minimum and maximum in tables. The chosen level of statistical significance was $\mathrm{p}<0.05$.

\section{Results}

Thickness of the hip joint sheath and articular effusion were measured bilaterally in 106 hemodialysis patients and the measured values were compared with those recorded in 51 control subjects. Measurement results were compared according to the length of hemodialysis, body side, age, sex, $\beta 2$-microglobulin concentration, and measured thickness of the hip joint sheath and articular effusion in control subjects. The mean age of patients undergoing hemodialysis at the time of examination was 64.0 (range 28.2-87.4) years. There were 55 male patients, mean age 60.5 (28.2-87.4) years and 51 female patients, mean age 67.9 (30.7-82.0) years. The mean length of hemodialysis in 18-50, 51-65 and $>65$ age groups was 16, 53 and 123 months, respectively, mean 56.3 months. In control group consisting of 51 healthy volunteers, the mean age was 62.6 (40.0-86.4) years. There were 25 male subjects, mean age 61.6 (40.0-86.4) years and 26 female subjects, mean age 63.6 (40.5-81.0) years. There was no statistically significant difference in age between hemodialysis patients and controls (P $\square 0.05$ ). The US measured thickness of hip joint sheath and articular effusion in control group according to age groups is shown in Tables 1 and 2, respectively.

\begin{tabular}{||c|c|c|c|c||}
\hline \multirow{2}{*}{ Age (yrs) } & & \multicolumn{3}{|c|}{ Hip joint sheath thickness (mm) } \\
\cline { 2 - 5 } & $\mathrm{n}$ & $\mathrm{M}$ & Min & Max \\
\hline $18-50$ & 7 & 5.36 & 3.90 & 7.50 \\
\hline $51-65$ & 21 & 5.33 & 3.90 & 7.30 \\
\hline$>65$ & 23 & 4.69 & 3.10 & 7.50 \\
\hline Total & 51 & 5.04 & 3.10 & 7.50 \\
\hline
\end{tabular}

$\mathrm{n}=$ number of subjects; $\mathrm{M}=$ mean $(\mathrm{mm})$

Table 1. Number of subjects, age, and hip joint sheath thickness in control group.

\begin{tabular}{||c|c|c|c|c||}
\hline \multirow{2}{*}{ Age (yrs) } & & \multicolumn{3}{|c|}{ Articular effusion thickness (mm) } \\
\cline { 2 - 5 } & $\mathrm{n}$ & $\mathrm{M}$ & Min & Max \\
\hline $18-50$ & 7 & 4.11 & 1.10 & 6.40 \\
\hline $51-65$ & 21 & 4.85 & 0.80 & 7.10 \\
\hline$>65$ & 23 & 4.44 & 2.10 & 7.00 \\
\hline Total & 51 & 4.56 & 0.80 & 7.10 \\
\hline
\end{tabular}

$\mathrm{n}=$ number of subjects; $\mathrm{M}=$ mean $(\mathrm{mm})$

Table 2. Number of subjects, age, and articular effusion thickness in control group. 
The US measured thickness of the hip joint sheath and articular effusion using anterior longitudinal approach with the probe parallel to the femoral neck axis is presented in Figure 1 .

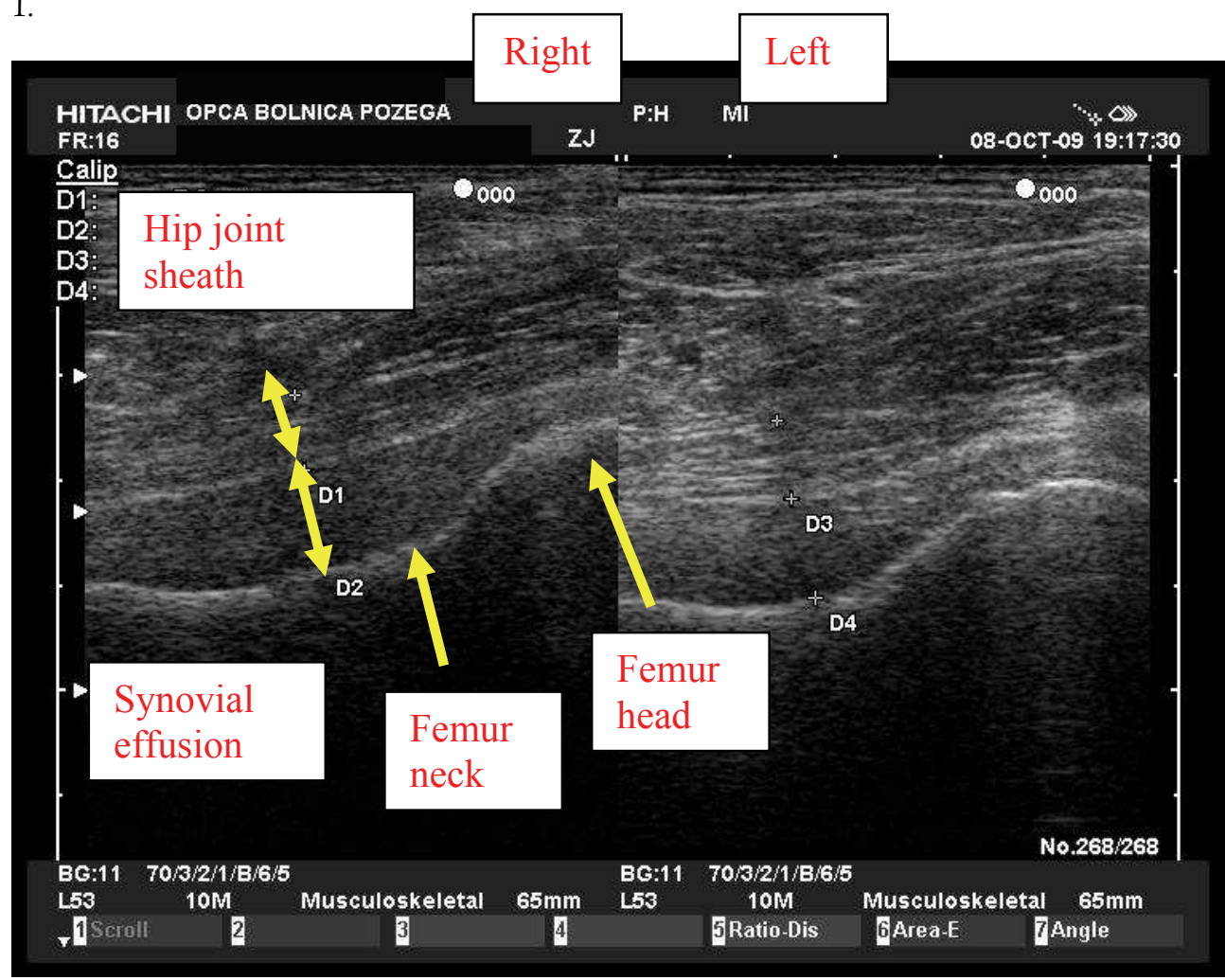

Fig. 1. US image of the hip joint sheath and intra-articular effusion.

The US measured thickness of hip joint sheath according to the length of hemodialysis and patient age is presented in Table $3 \mathrm{~A}$ and $\mathrm{B}$.

\begin{tabular}{|c|c|c|c|c|c|c|c|c|c|c|c|c|}
\hline \multirow{3}{*}{$\begin{array}{l}\text { Age } \\
\text { (yrs) }\end{array}$} & \multicolumn{12}{|c|}{ Length of hemodialysis } \\
\hline & \multicolumn{4}{|c|}{$<36$ months } & \multicolumn{4}{|c|}{ 36-72 months } & \multicolumn{4}{|c|}{$>72$ months } \\
\hline & $\mathrm{n}$ & M & Min & $\operatorname{Max}$ & $\mathrm{n}$ & M & Min & $\operatorname{Max}$ & $\mathrm{n}$ & M & Min & $\operatorname{Max}$ \\
\hline $18-50$ & 8 & 5.30 & 3.90 & 6.50 & 5 & 6.32 & 5.10 & 7.40 & 3 & 7.93 & 6.70 & 9.00 \\
\hline $51-65$ & 10 & 5.45 & 4.00 & 6.90 & 9 & 6.44 & 5.00 & 8.70 & 7 & 6.86 & 4.20 & 8.50 \\
\hline$>65$ & 24 & 5.53 & 3.10 & 7.10 & 23 & 6.70 & 5.10 & 8.00 & 17 & 7.20 & 3.30 & 10.3 \\
\hline Total & 42 & 5.47 & 3.10 & 7.10 & 37 & 6.59 & 5.00 & 8.70 & 27 & 7.19 & 3.30 & 10.3 \\
\hline
\end{tabular}

$\mathrm{n}=$ number of patients; $\mathrm{M}=$ mean $(\mathrm{mm})$

Table 3A. Number of patients and hip joint sheath thickness according to patient age and length of hemodialysis. 


\begin{tabular}{||c|c|c|c|c||}
\hline \multirow{3}{*}{ Age (yrs) } & \multicolumn{4}{|c||}{ Length of hemodialysis } \\
\cline { 2 - 5 } & \multicolumn{4}{|c||}{ Total } \\
\cline { 2 - 5 } & $\mathrm{n}$ & $\mathrm{M}$ & Min & Max \\
\hline $18-50$ & 16 & 6.11 & 3.90 & 9.00 \\
\hline $51-65$ & 26 & 6.17 & 4.00 & 8.70 \\
\hline$>65$ & 64 & 6.39 & 3.10 & 10.3 \\
\hline Total & 106 & 6.30 & 3.10 & 10.3 \\
\hline
\end{tabular}

$\mathrm{n}=$ number of patietns; $\mathrm{M}=$ mean $(\mathrm{mm})$

Table 3B. Number of patients and hip joint sheath thickness according to patient age and length of hemodialysis (total).

Simple analysis of variance for independent samples with the length of hemodialysis (categorized into three groups) as independent variable, and hip joint sheath thickness and articular effusion as dependent variables was performed to assess the impact of hemodialysis duration on thickness of the hip joint sheath and articular effusion. A statistically significant difference was found in thickness of the hip joint sheath and articular effusion between groups of patients with different length of hemodialysis, as indicated by the results of simple analysis of variance: joint sheath thickness $\mathrm{F}=21.319 ; \mathrm{df}=2 / 103 ; P<0.01$ on the right; and $\mathrm{F}=21.011 ; \mathrm{df}=2 / 103 ; P<0.01$ on the left; and articular effusion: $\mathrm{F}=3.227$; $\mathrm{df}=2 / 103 ; P<0.05$ on the right; and $\mathrm{F}=4.479 ; \mathrm{df}=2 / 103 ; P<0.05$ on the left. Subsequent Tukey HSD test yielded a statistically significant difference in the hip joint sheath thickness among the three groups of hemodialysis patients. A statistically significant difference was found in the hip joint sheath thickness between the groups of patients with the length of hemodialysis $<36$ months and 36-72 months, $<36$ months and $>72$ months, 36-72 months and $>72$ months $(P<0.01$ all). Thickness of the hip joint sheath increased with the duration of hemodialysis. These differences were statistically significant on both the left and right side of the body. Subsequent Tukey HSD test yielded a statistically significant difference in hip joint intra-articular effusion between the groups of patients on hemodialysis for $<36$ months and $>72$ months $(P<0.05)$. The magnitude of hip joint intra-articular effusion was significantly lower in the group of patients on hemodialysis for $<36$ months. Accordingly, the length of hemodialysis influenced the magnitude of articular effusion. Thickness of the hip joint sheath and articular effusion increased with the length of hemodialysis. Differences were statistically significant bilaterally. Comparison of the hip joint sheath thickness and articular effusion according to body sides yielded no statistically significant difference, as indicated by the nonsignificant t-ratio (joint sheath thickness: $t=1.739 ; \mathrm{df}=105$, and articular effusion: $\mathrm{t}=0.633 ; \mathrm{df}=105 ; P>0.05$ both). Hip joint sheath thickness and articular effusion were compared according to patient sex by use of t-test for independent samples. A statistically significant sex difference was found in both hip joint sheath thickness and articular effusion bilaterally, as follows: hip joint sheath thickness $t=2.479 ; \mathrm{df}=104 ; P<0.05$ (right) and $\mathrm{t}=3.138 ; \mathrm{df}=104 ; P<0.01$ (left), and articular effusion $\mathrm{t}=2.075 ; \mathrm{df}=104$ (right) and $\mathrm{t}=2.332 ; \mathrm{df}=104$ (left); $P<0.05$ both. The measured thickness of the hip joint sheath and articular effusion were greater bilaterally in male than in female patients. Simple analysis of variance for independent samples with age (categorized into three groups) as independent variable, and hip joint sheath thickness and articular effusion as dependent variables was 
performed to assess the impact of age on hip joint sheath thickness and articular effusion. The analysis of variance yielded the following results: $\mathrm{F}=0.437 ; \mathrm{df}=2 / 103$ (right) and $\mathrm{F}=0.496 ; \mathrm{df}=2 / 103$ (left); $P>0.05$ both. There was no statistically significant difference in the hip joint sheath thickness among the three age groups on either side of the body. The same analysis of variance was also performed with various age groups and magnitude of articular effusion in the hip region, with the following results: $\mathrm{F}=3.252 ; \mathrm{df}=2 / 103$ (right) and $\mathrm{F}=3.023$; $\mathrm{df}=2 / 103$ (left); $P>0.05$ both. There was no statistically significant difference in the magnitude of articular effusion among the three age groups on either side of the body. Accordingly, patient age was not found to influence thickness of the hip joint sheath and intra-articular effusion.

Beta2-microglobulin concentration was determined before hemodialysis in the three patient age groups having undergone hemodialysis for a variable period of time. These results are shown in Table $4 \mathrm{~A}$ and $\mathrm{B}$.

\begin{tabular}{||c|c|c|c|c|c|c|c|c||}
\hline \multirow{3}{*}{ Age (yrs) } & \multicolumn{9}{|c||}{ Length of hemodialysis } \\
\cline { 2 - 9 } & \multicolumn{3}{|c|}{$<36$ months } & \multicolumn{4}{c||}{$36-72$ months } \\
\cline { 2 - 9 } & $\mathrm{n}$ & $\mathrm{M}$ & Min & Max & $\mathrm{n}$ & $\mathrm{M}$ & Min & Max \\
\hline $18-50$ & 8 & 31.020 & 19.874 & 42.662 & 5 & 34.331 & 25.580 & 43.688 \\
\hline $51-65$ & 10 & 28.586 & 10.115 & 50.864 & 9 & 29.241 & 11.032 & 41.376 \\
\hline$>65$ & 24 & 26.793 & 10.116 & 42.129 & 23 & 30.704 & 15.552 & 44.824 \\
\hline Total & 42 & 28.025 & 10.115 & 50.864 & 37 & 30.838 & 11.032 & 44.824 \\
\hline
\end{tabular}

$\mathrm{n}=$ number of patients; $\mathrm{M}=$ mean $\beta 2$-microglobulin concentration $(\mathrm{mg} / \mathrm{L})$

Table 4A. $\beta 2$-microglobulin concentration in three patient age groups undergoing hemodialysis for $<36$ months and 36-72 months.

\begin{tabular}{|c|c|c|c|c|c|c|c|c||}
\hline \multirow{3}{*}{ Age (yrs) } & \multicolumn{9}{|c||}{ Length of hemodialysis } \\
\cline { 2 - 10 } & \multicolumn{3}{|c|}{$>72$ months } & \multicolumn{4}{c||}{ Total } \\
\cline { 2 - 9 } & $\mathrm{n}$ & $\mathrm{M}$ & Min & Max & $\mathrm{n}$ & $\mathrm{M}$ & Min & Max \\
\hline $18-50$ & 3 & 44.340 & 35.915 & 53.147 & 16 & 34.552 & 19.874 & 53.147 \\
\hline $51-65$ & 7 & 32.122 & 16.188 & 51.791 & 26 & 29.764 & 10.115 & 51.797 \\
\hline$>65$ & 17 & 32.069 & 10.328 & 47.997 & 64 & 29.600 & 10.116 & 47.997 \\
\hline Total & 27 & 33.446 & 10.328 & 53.147 & 106 & 30.388 & 10.115 & 53.147 \\
\hline
\end{tabular}

$\mathrm{n}=$ number of patients; $\mathrm{M}=$ mean $\beta 2$-microglobulin concentration $(\mathrm{mg} / \mathrm{L})$

Table 4B. $\beta 2$-microglobulin concentration in three patient age groups undergoing hemodialysis for $<72$ months and total.

Simple analysis of variance for independent samples with the length of hemodialysis (categorized into three groups) as independent variable, and pre-hemodialysis 32 microglobulin concentration as dependent variable performed to assess the possible impact of the length of hemodialysis on pre-hemodialysis $\beta 2$-microglobulin concentration produced the following results: $\mathrm{F}=3.262 ; \mathrm{df}=2 / 103 ; P<0.05$. Subsequent Tukey HSD test yielded a statistically significant difference in pre-hemodialysis $\beta 2$-microglobulin concentration between patient groups with hemodialysis duration $<36$ and $>72$ months $(P<0.05)$. Pre- 
hemodialysis $\beta 2$-microglobulin concentration was higher in the patient group with $>72$ month hemodialysis duration as compared with those with $<36$ month hemodialysis duration. Accordingly, longer hemodialysis duration was associated with higher $\beta 2-$ microglobulin concentration. In addition, $\beta 2$-microglobulin concentration was correlated with patient age to assess the possible effect of age on pre-hemodialysis $\beta 2$-microglobulin concentration. Simple analysis of variance for independent samples with age (categorized into three groups) as independent variable and pre-hemodialysis $\beta 2$-microglobulin concentration as dependent variable was done to check for statistically significant differences in $\beta 2$-microglobulin concentration among patients from different age groups. The analysis of variance yielded the following results: $\mathrm{F}=2.114 ; \mathrm{df}=2 / 103 ; P \square 0.05$. Accordingly, there was no statistically significant difference in pre-hemodialysis $\beta 2-$ microglobulin concentration among the three age groups; thus, patient age had no impact on pre-hemodialysis $\beta 2$-microglobulin concentration in serum. The hip joint sheath thickness relative to $\beta 2$-microglobulin concentration was compared between groups of patients with different length of hemodialysis. A statistically significant correlation between $\beta 2$-microglobulin concentration and hip joint sheath thickness was recorded in the group of patients on hemodialysis for up to 36 months on the right side $(\mathrm{r}=0.310 ; P<0.05)$. In this group of patients, the higher the $\beta 2$-microglobulin concentration, the higher was the hip joint sheath thickness. In the other two groups of patients on hemodialysis for 36-72 months and $>72$ months there was no statistically significant correlation between $\beta 2$-microglobulin concentration and hip joint sheath thickness on either side of the body. The magnitude of hip joint intra-articular effusion and $\beta 2$-microglobulin concentration were correlated in the groups of patients with different length of hemodialysis, yielding no statistically significant correlation between the two parameters in any of the patient groups. Pre-hemodialysis $\beta 2-$ microglobulin concentration had no effect on the magnitude of hip joint intra-articular effusion in any of the patient groups with different length of hemodialysis. The mean $\beta 2-$ microglobulin concentration was $1.662 \mathrm{mg} / \mathrm{L}$ in control group and $30.388 \mathrm{mg} / \mathrm{L}$ in overall patient group $(28.025,30.838$ and $33.446 \mathrm{mg} / \mathrm{L}$ in patient groups on hemodialysis for $<36$, 36-72 and $>72$ months, respectively), i.e. 18.3-fold concentration in control group $(P<0.05)$. The mean $\beta 2$-microglobulin concentrations recorded in three control age groups are shown in Table 5.

\begin{tabular}{||c|c|c|c|c||}
\hline \multirow{2}{*}{ Age (yrs) } & \multicolumn{4}{|c|}{ Total } \\
\cline { 2 - 5 } & $\mathrm{n}$ & $\mathrm{M}$ & Min & Max \\
\hline $18-50$ & 7 & 1.133 & 0.942 & 1.537 \\
\hline $51-65$ & 21 & 1.541 & 0.963 & 2.617 \\
\hline$>65$ & 23 & 1.934 & 1.130 & 2.836 \\
\hline Total & 51 & 1.662 & 0.942 & 2.836 \\
\hline
\end{tabular}

$\mathrm{n}=$ number of subjects; $\mathrm{M}=$ mean $\beta 2$-microglobulin concentration $(\mathrm{mg} / \mathrm{L})$

Table 5. $\beta 2$-microglobulin concentration in three control age groups. 
Hip joint sheath thickness was compared between patient and control group and tested for statistically significant between-group difference by use of t-test for independent samples, which yielded the following result: $t=1.982 ; \mathrm{df}=91 ; P>0.05$. There was no statistically significant difference in hip joint sheath thickness between control group and patient group on hemodialysis for $<36$ months. However, comparison of hip joint sheath thickness between control group and patient groups on hemodialysis for 36-72 and >72 months yielded a statistically significant difference bilaterally, i.e. thickness of the hip joint sheath was statistically significantly greater in both patient groups. Thickness of articular effusion in the hip region was also compared between control group and patient groups with different length of hemodialysis. Intra-articular effusion was statistically significantly greater bilaterally in all three patient groups having undergone hemodialysis for $<36,36-72$ and $>72$ months as compared to control subjects. The length of hemodialysis influenced the rate of hip joint intra-articular effusion. Thickness of the hip joint intra-articular effusion according to patient age and length of hemodialysis is shown in Table $6 \mathrm{~A}$ and $\mathrm{B}$.

\begin{tabular}{|c|c|c|c|c|c|c|c|c|c|c|c|c|}
\hline \multirow{3}{*}{$\begin{array}{l}\text { Age } \\
\text { (yrs) }\end{array}$} & \multicolumn{12}{|c|}{ Length of hemodialysis } \\
\hline & \multicolumn{4}{|c|}{$<36$ months } & \multicolumn{4}{|c|}{ 36-72 months } & \multicolumn{4}{|c|}{$>72$ months } \\
\hline & $\mathrm{n}$ & $\mathrm{M}$ & Min & $\operatorname{Max}$ & $\mathrm{n}$ & $\mathrm{M}$ & Min & Max & $\mathrm{n}$ & $\mathrm{M}$ & Min & Max \\
\hline $18-50$ & 8 & 5.26 & 3.50 & 6.90 & 5 & 6.02 & 2.90 & 9.70 & 3 & 6.30 & 5.10 & 8.60 \\
\hline $51-65$ & 10 & 5.41 & 3.20 & 7.70 & 9 & 5.87 & 3.30 & 8.90 & 7 & 6.40 & 4.20 & 8.30 \\
\hline$>65$ & 24 & 6.14 & 3.90 & 11.5 & 23 & 6.86 & 4.40 & 9.40 & 17 & 7.06 & 2.70 & 11.0 \\
\hline Total & 42 & 5.80 & 3.20 & 11.5 & 37 & 6.50 & 2.90 & 9.70 & 27 & 6.80 & 2.70 & 11.0 \\
\hline
\end{tabular}

$\mathrm{n}=$ number of subjects; $\mathrm{M}=$ mean (mm)

Table 6A. Number of subjects and hip joint intra-articular effusion according to age and length of hemodialysis.

\begin{tabular}{||c|c|c|c|c||}
\hline \multirow{2}{*}{ Age (yrs) } & \multicolumn{4}{|c||}{ Length of hemodialysis } \\
\cline { 2 - 5 } & \multicolumn{4}{|c||}{ Total } \\
\cline { 2 - 5 } & $\mathrm{n}$ & $\mathrm{M}$ & Min & Max \\
\hline $18-50$ & 16 & 5.69 & 2.90 & 9.70 \\
\hline $51-65$ & 26 & 5.84 & 3.20 & 8.90 \\
\hline$>65$ & 64 & 6.64 & 2.70 & 11.5 \\
\hline Total & 106 & 6.30 & 2.70 & 11.5 \\
\hline
\end{tabular}

$\mathrm{n}=$ number of subjects; $\mathrm{M}=$ mean $(\mathrm{mm})$

Table 6B. Number of subjects and hip joint intra-articular thickness according to age and length of hemodialysis (total). 


\section{Discussion}

Complications involving the osteoarticular system are common in CRF patients. These complications develop at a slow rate, their clinical signs make only the tip of the iceberg that mostly indicate an advanced stage of the disease and are generally due to renal osteodystrophy and hemodialysis-related amyloidosis. Increased intra-articular effusion and greater hip joint sheath thickness are not specific changes and may occur consequentially to many other pathologic conditions. There are numerous diagnostic procedures to detect and follow-up changes in the osteoarticular system. As most of these methods are associated with high requirements related to duration, price, equipment, room, exposure to ionizing radiation, invasiveness and potential complications, ultrasonography imposes itself as an inexpensive, noninvasive, presumptive, widely available and repeatable examination free from ionizing radiation. As dialysis-related amyloidosis is a multifactorial disease and its pathogenesis has not yet been fully clarified, we embarked upon this study to assess the effect of patient age, hemodialysis duration and $\beta 2$-microglobulin concentration on morphological changes in the hip region. Thickness of the hip joint sheath and magnitude of intra-articular effusion were found to be proportional to the length of hemodialysis. Thus, early lesions of the osteoarticular system can be detected by measuring the magnitude of articular effusion in the hip area. The increase in intra-articular effusion could be explained by changes involving joint sheath and cartilage due to hemodialysisrelated amyloidosis and initial signs of chronic arthropathy in patients with dialysis-related amyloidosis. Biochemical and histologic tests of joint structures can explain the presence of articular effusion and lesions involving the osteoarticular system. In CRF patients, the level of advanced glycation endproducts (AGE) is considerably elevated. These endproducts are formed in the state of uremia via nonenzymatic pathway, primarily by oxidative reactions as part of chronic inflammation in CRF patients (Miyata et al., 1999; Sugiyama et al., 1998; Wada et al., 1999;). Elevated AGE levels are found in all tissues, in particular collagenous amyloid structures, which is produced at an increased rate due to impaired metabolism and higher production of $\beta 2$-microglobulin as a major amyloid component. AGEs are deposited in collagen to cause its structural changes and making it liable to mechanical changes (Miyata et al., 1994). The amount of articular effusion can be influenced by AGEs, which attract monocytes via chemotaxis, stimulating them for synthesis of the tumor necrosis factor- $\alpha$ (TNF- $\alpha$ ) and interleukin-1 $\beta$ (IL-1 $\beta$ ) cytokines. The synovial sheath intima contains macrophages, while fibroblasts account for $70 \%$ of intimal cells. Cytokines stimulate synovial fibroblasts for collagenase synthesis. Thus, synovial fibroblasts may be involved in the cellular inflammatory reaction associated with joint damage and destruction in hemodialysis-related amyloidosis (Koski et al., 1989). Protein matrix is degraded by collagenase. Degraded collagen attracts monocytes via chemotaxis, stimulating them for further TNF- $\alpha$ and IL-1 $\beta$ synthesis, thus creating a vicious circle (Miyata et al., 1994; Koski et al., 1989). Cytokines act upon the joint cartilage collagen and irritate synovial sheath of the joint, resulting in greater amount of intra-articular fluid. These biochemical reactions are supported by histologic studies demonstrating the initial occurrence of amyloid deposits on the joint cartilage. Burgeson and Nimmi (1992) found these amyloid deposits to be initially accumulated in the cartilage predominated by type I collagen. Jadoul et al. (1997) used histology to detect initial accumulation of paucicellular amyloid deposits surrounded by macrophages on joint cartilage, supporting the inflammatory nature of amyloid deposits. Zhang et al. (2002) report on $\beta 2$-microglobulin inhibitory action on joint cartilage 
chondrocytes. Subsequent changes involve synovium, joint sheaths and tendons. Menerey et al. (1988) demonstrated the presence of amyloid in synovial fluid. These alterations may mark the onset of degenerative changes, erosions and effusions in the joints. Jadoul et al. (1993) found thickness of the hip joint sheath and supraspinous muscle tendon to correlate with the length of hemodialysis in 49 patients undergoing hemodialysis for a mean of 97 months. After 21 months of hemodialysis, measurement was repeated in 16 patients to show a statistically significant increase in the hip joint sheath thickness in nine patients (from $7.0 \pm 0.8 \mathrm{~mm}$ to $8.2 \pm 2.3 \mathrm{~mm}$ ). On repeat measurement, there was no statistically significant increase in thickness of the supraspinous muscle tendon (from $6.6 \pm 0.4 \mathrm{~mm}$ to $7.0 \pm 0.8 \mathrm{~mm}$ ). Jeloka et al. (2001) compared hip joint sheath thickness between 30 patients undergoing hemodialysis for a mean of 7.1 years and 20 control subjects. The mean hip joint sheath thickness was $8.19 \mathrm{~mm}$ and $5.06 \mathrm{~mm}$, and mean serum $\beta 2$-microglobulin concentration $25.6 \pm 4.12 \mathrm{mg} / \mathrm{L}$ and $2.6 \pm 1.73 \mathrm{mg} / \mathrm{L}$ in patients and control subjects, respectively. In hemodialysis patients, serum $\beta 2$-microglobulin concentration was statistically significantly lower while on hemodialysis with low-flux hemodialyzers as compared with the time on hemodialysis with high-flux hemodialyzers. The authors demonstrated correlation between the hip joint sheath thickness and the length of hemodialysis. The longer the time of hemodialysis, the greater was the hip joint sheath thickness. The authors conclude that osteoarticular system changes in hemodialysis patients can be followed-up by measurement of the hip joint sheath thickness. Most authors agree that changes in the osteoarticular system are related to the length of hemodialysis (Jadoul et al., 1993; Jeloka et al., 2001). In the present study, we found no statistically significant difference in $\beta 2$-microglobulin concentration among the three patient age groups, nor recorded any effect of age on morphological changes in the hip area. There are literature reports on the carpal tunnel syndrome, amyloid arthropathy and amyloid bone cysts to be more common in elderly patients (Denesh \& Ho, 2001; Shin et al., 2008).

The mechanism by which patient age influences the prevalence of complications in hemodialysis patients remains unknown. The concentration of AGEs is higher in elderly subjects (Sell \& Monnier, 1990). As AGEs influence collagen metabolism, it may explain the impact of age on anatomic structure changes in this population. Schiffl et al. (2000) investigated the prevalence of complications involving osteoarticular system in hemodialysis patients aged $<55$ and $>55$. The latter had a higher rate of complications including carpal tunnel syndrome, amyloid arthropathy and bone cysts as compared to patients aged $<55$ at the time of starting hemodialysis. The older patient age, the higher was the rate of complications. The time elapsed from starting hemodialysis to the onset of complications was shorter in older than in younger patients. Kurer et al. (1991) found carpal tunnel syndrome to be more common in elderly patients and in those starting hemodialysis at an older age. In older patients, carpal tunnel syndrome developed after a shorter period of hemodialysis than in younger ones. However, opposite results have also been reported in the literature. Using the Glasgow Ultrasound Enthesitis Scoring System (GUESS) scale, Kerimoglu et al. (2007) found changes of the osteoarticular system anatomic structures in hemodialysis patients to be related to the length of hemodialysis, while demonstrating no effect of patient age and $\beta 2$-microglobulin concentration. Weybright et al. (2003) point to the possible misinterpretations and false-positive results of US measurement of articular effusion in the hip area. Ultrasonography performance is limited in overweight patients. Synovial membrane of the hip joint covers fibrous membrane and cannot be visualized on US. Hypoechogenic synovia may push as the 
articular sheath, thus yielding an image of articular effusion. This is especially pronounced in obese subjects, where hypoechogenic synovia may appear as articular effusion on US. In our study, $\beta 2$-microglobulin concentration influenced the hip joint sheath thickness in the group of patients on hemodialysis for $<36$ months, whereas no statistically significant correlation was observed in the other two patient groups. Serum $\beta 2$-microglobulin concentration had no effect on the amount of articular effusion in the hip area in any patient group with different length of hemodialysis. In addition, there was no statistically significant difference in $\beta 2$-microglobulin concentration among the three patient groups, however, $\beta 2$-microglobulin concentration was higher in patients with longer hemodialysis duration. A high serum $\beta 2$-microglobulin concentration is one of the preconditions for the development of hemodialysis-related amyloidosis; therefore, higher $\beta 2$-microglobulin concentration is expected to be associated with more pronounced morphological changes of anatomic structures. There are no reports on hemodialysisrelated amyloidosis in patients with $\beta 2$-microglobulin concentration $<10 \mathrm{mg} / \mathrm{L}$ (Farrell \& Bastani, 1997). Because of different dialyzer membrane properties, $\beta 2$-microglobulin concentration is by $30 \%$ lower in patients on hemodialysis with low-flux hemodialyzers (Jadoul, 1998). In their study including 50 patients, McCarthy et al. (1997) found residual kidney function to be preserved for a longer time in patients on hemodialysis with highflux hemodialyzers. During the first 12-24 months of hemodialysis, $\beta 2$-microglobulin concentration also depends on residual kidney function, i.e. the longer it is preserved, the later the onset of amyloidosis complications (Schiffl et al., 2000). The membrane of highflux hemodialyzers is characterized by higher biocompatibility and lower rate of stimulating $\beta 2$-microglobulin concentration production through complement activation. The high-flux dialyzer membrane can remove $\beta 2$-microglobulin molecules and AGE modified proteins, thus influencing the process of amyloid formation (Henle et al., 1999; Jadoul, 1998). Therefore, the use of high-flux dialyzers is expected to be associated with a lower rate of complications involving the osteoarticular system (Geyo, 2001). Beta2microglobulin concentration does not correlate with the activity of dialysis-related amyloidosis, thus serum $\beta 2$-microglobulin concentration is not a diagnostic test to determine the severity of dialysis-related amyloidosis (Farrell \& Bastani, 1997; Koski et al., 1989). A number of studies have confirmed that clinical symptoms of complications involving the osteoarticular system are more common in patients undergoing hemodialysis for a prolonged period of time, as well as in those with higher $\beta 2-$ microglobulin concentration (Barišić et al., 2007).

Shin et al. (2008) compared two groups of patients with different $\beta 2$-microglobulin concentration and found the prevalence of carpal tunnel syndrome to be lower in patients with lower $\beta 2$-microglobulin concentration. Barišić et al. (2007) report on a higher $\beta 2-$ microglobulin concentration in the group of hemodialysis patients articular pain as compared with those free from articular pain. In contrast, Kerimoglu et al. (2007) found no statistically significant correlation between GUESS scale and serum $\beta 2$-microglobulin concentration. In the present study, intra-articular effusion in the hip area was statistically significantly greater bilaterally in all three hemodialysis patient groups as compared with control group. Difference in the hip joint sheath thickness did not reach statistical significance between control group and the group of patients on hemodialysis for $<36$ months, but was statistically significant in the groups of patients on hemodialysis for 36-72 and $>72$ months. 


\section{Conclusion}

The present study demonstrated that changes involving osteoarticular system soft tissues in CRF patients could be followed-up by use of US. Although the National Kidney Foundation Kidney Disease Outcomes Quality Initiative (NKF KDOQI, 2003) recommendations do not recommend routine follow up of CRF patients by $\beta 2$-microglobulin amyloidosis because there is no therapeutic option other than kidney transplantation for hemodialysis-related amyloidosis, we consider US a useful and widely available diagnostic method to detect and follow-up soft tissue changes in hemodialysis patients. In our study, pre-hemodialysis serum 32 -microglobulin concentration did not influence the magnitude of articular effusion, but did influence hip joint sheath thickness in patients undergoing hemodialysis for $<36$ months, with no statistically significant correlation recorded in the other two groups of patients. Morphological changes correlated with the length of hemodialysis, but not with patient age. As the osteoarticular system changes are multifactorial, additional studies are needed to determine the effect of particular factors on these changes in CRF patients. Research should be focused on complications in patients undergoing hemodialysis with high-flux dialyzers in order to identify the possible impact of the type of hemodialyzers on osteoarticular system changes. US study is the method of choice to follow-up the dynamics of changes involving soft tissue structures (Bother et al., 2006; Drüeke, 1999; Kay et al., 1962; Kerimoglu et al., 2007; Kiss et al., 2005; Negi et al., 1995). Early and asymptomatic lesions of the joints, tendons and ligaments can be detected by US (Barišić et al., 2002; Jeloka et al., 2001; Lanteri et al., 2000; Takahashi et al., 2002). The need for the best possible care of hemodialysis patients points to the use of US as a adjunctive method to clinical examination to assess soft tissue changes of the osteoarticular system by providing better insight into the pathology of articular tendons, ligaments, cartilage and effusion (Backhaus et al., 2001; Takahashi et al., 2002). US analysis of morphological changes of the osteoarticular system can be of prognostic value in patients undergoing hemodialysis. Maintaining good function of the osteoarticular system helps the CRF patients achieve appropriate social inclusion and better quality of life, while reducing the cost of treatment for severe complications.

\section{Acknowledgments}

The authors would like to ancnowledge the LIMA - O.I. d.o.o. Zagreb for their financial support for this project.

\section{References}

Al-Taee IK, Al-Safar JJ, Al-Falahi YS, Al-Shamma IA. The Clinical Significance of $\beta 2-$ microglobulin un End-Stage Renal Disease. Saudi J Kidney Dis Transpl 2003;14(4):492-6.

Backhaus M, Burmester GR, Gerber T, Grassi W, Machold KP, Swen WA, i sur. Gudelines for muscolosceletal ultrasound in reumatology. Ann Rheum Dis 2001;60(7): 641-9.

Barišić I, Ljutić D, Vlak T, Bekavac J, Janković S. Laboratory and sonographic findings in dialyzed patients with bilateral chronic knee pain versus dialyzed asymptomatic patients. Coll Antropol 2007;31(2):489-94. 
Barišić I, Wilhelm V, Štambuk N, Karaman K. Janković S, Konjevoda P, i sur. Machine Learning Based Analysis of Biochemical and Morphological Parameters in Patients with Dialysis Releated Amyloidosis. Croat Chem Acta 2002;75(4):93544.

Bother LA, Barbosa ABR, Sicca JA, Oliviera GR, Silva MRC, Germano M, i sur. Ultrasonography evaluation of tendon thickness in haemodialysis patients. Einstein 2006;4(4):303-8.

Burgeson RE, Nimmi ME. Collagen types. Molecular structure and tissue distribution. Clin Orthop Relat Res 1992;282:250-72.

Connors LH, Shirahama T, Sipe JD, Skinner M, Fenves A,Cohen AS: Formation of amyloid fibrils from intact $\beta 2$-microglobulin. Biochem Biophys Res Commun 1985;131:10638.

Denesh F, Ho LT. Dyalisis-releated amyloidosis: history and clinical manifestations. Semin Dial 2001;14(2):80-5.

Drüeke TB. Ekstraskeletal problems and amyloid. Kidney Int Suppl 1999;73:S89-93.

Farrell J, Bastani B. Beta 2-microglobulin amyloidosis in chronic dialysis patients: a case report and review of the literature. J Am Soc Nephrol 1997;8:509-14.

Fitzpatrick DC, Jebson PJL, Madey SM, Steyers CM. Upper extremity musculosceletal manifestations of dialysis-associated amyloidosis. Iowa Orthop J 1996;16:13538.

Floege J, Schäffer J, Koch KM. Scintigraphic methods to detect beta2-microglobulin associated amyloidosis (Abeta2-microglobulin amyloidosis). Nephrol Dial Transplant 2001;16 Supp 14:12-6.

Fukuda K, Yamamoto H. Dialysis-releated amyloidosis. Semin Musculoscelet Radiol 2001;5(2):113-9.

Geyo F. Beta 2-microglobulin and dialysis-releated amyloidosis. Rinsho Byori 2001;49(3):244-8.

Geyo F, Yamada T, Odani S, Nakagawa Y, Arakawa M, Kunimoto T, i sur. A new form of amyloid protein associated with chronic hemodialysis was identified as beta 2microglobulin. Biochem Biophys Res Commun 1985;129:701-6.

Hawkins PN, Lavender JP, Pepys MB.Evaluation of systemic amyloidosis by scintigraphy with 123I-labeled serum amyloid P component. N Engl J Med 1990 Aug 23;323(8):542-3.

Henle T, Deppisch R, Beck W, Hergesell O, Hänsch GM, Ritz E. Advanced glycated endproducts (AGE) during haemodialysis treatment: discrepant results with different methodologies reflecting the heterogeneity of AGE compounds. Nephrol Dial Transplant 1999;14(8):1968-75.

Ikegava N, Hishida A, Sawada K, Furuhashi M, Maruyama Y, Kumagai H, i sur. Ultrasonographic evaluation of the carpal tunnel syndrome in hemodialysis patients. Clin Nephrol 1995;44(4):231-7.

Jadoul M. Dialysis-releated amyloidosis:importance of biocompatibility and age. Nephrol Dial Transplant 1998;13 Suppl 7:61-4. 
Jadoul M, Garbar C, Noel H, Sennesael J, Vanholder R, Bernaert P. et al. Histological prevalence of beta2-microglobulin amyloidosis in haemodialysis: A prospective post-mortem study. Kidney Int 1997;92:1928-52.

Jadoul M, Malghem J, vande Berg, B, van Ypersele de Strihou C. Ultrasonographic detection of thickened joint capsules and tendons as marker of dialysis-releated amyloidosis: a cross-sectional and longitudinal study. Nephrol Dial Transplant 1993;8(10): 1104-9.

Jeloka T, Mathur MD, Kaur R, Kohli R, Singh NP, Rizvi SNA. $\beta 2$ Microglobulin in chronic renal failure and effect of different dialyser membrane on its clearance. Indian J Nephrol 2001;11:160-4.

Jimenez RE, Price DA, Pinkus GS, Owen WF Jr, Lazarus JM, Kay J, i sur. Development of gastrointestinal beta2-microglobulin amyloidosis correlates with time on dialysis. Am J Surg Pathol 1998;22(6):729-35.

Kay J, Benson CB, Lester S, Corson JM, Pinkus GS, Lazarus JM, i sur. Utility of highresolution ultrasound for the diagnosis of dialysis-related amyloidosis. Arthritis Rheum 1992;35(8): 926-32.

Kelly A, Apostle K, Sanders D, Bailey H. Musculosceletal pain in dialysis-releated amyloidosis. Can J Surg 2007;50(4)305-6.

Kenzora JE. Dialysis carpal tunnel syndrome. Orthopaedics 1978;1:195-203.

Kerimoglu U, Hayran M, Ergen FB, Kirpanktur A, Turgan C. Sonographic evaluation of entheseal sites of the lower extremity in patients undergoing hemodialysis. J Clin Ultrasound 2007;35(8):417-23.

Ketteler M, Koch KM, Floege J. Imaging techniques in the diagnosis of dialysis-releated amyloidosis. Semin Dial 2001;14(2):90-3.

Kiss E, Keusch G, Zanetti M, Jung T, Schwarz A, Schocke M, i sur. Dialysis-releated amyloidosis revisited. AJR Am J Roentgenol 2005;185(6)1460-7.

Koski JM, Anthila PJ, Isomaki HA. Ultrasonography of the adult hip joint. Scand J Rheumatol 1989;18:113-7.

Kurer MH, Baillod RA, Madqwick JC. Musculosceletal maifestations of amyloidosis. A reiew of 83 patients on haemodyalysis for at least 10 years. J. Bone Joint Surg Br 1991;73(2):271-6.

Lanteri M, Ptasznik R, Hennesy O, Constable L, Dawborn JK. Ultrasound assesment of large joint amyloidosis in haemodialysis. Nephrology 2000;5:45-50.

Linke RP, Schäeffer J, Gielow P, Lindner P, Lottspeich F, Plückthun A, i sur. Production of recombinant humen beta2-microglobulin for scintigraphic diagnosis of amyloidosis in uremia and hemodialysis. Eur J Biochem 2000;267(3):627-33.

McCarthly JT, Jenson BM, Squillace DP, Williams AW. Improved preservation of residual function in chronic hemodialysis patients using polysulfone dialyzers. Am I Kidney Dis 1997;29:576-83.

Menerey K, Braunstein E, Brown M, Swartz R, Brown C, Fox IH. Musculosceletal symptoms related to arthropathy in patients receiving dialysis. J Rheumatol 1988; 15:1848-54.

Miyata T, Inagi R, Kurokawa K. Diagnosis, pathogenesis, and treatment of dialysis-related amyloidosis. Miner Electrolyte Metab 1999;25(1-2):114-7. 
Miyata T, Inagai R, Lida Y, Sato M, Yamada N, Oda O, Maeda K, Seo H. Involvement $\beta 2-$ microglobulin modified with advanced glycation end product in the pathogenesis of haemodialysis-associated amyloidosis. Induction of human monocyte chemotaxis and macrophage secretion of THF and IL-1. J Clin Invest 1994;93: 521-9.

Motomiya Y, Ando Y, Haraoka K, Sun X, Iwamoto H, Uchimura T, i sur. Circulating level of alfa2-microglobulin-beta2-microglobulin complex in hemodialysis patients. Kidney Int 2003;64(6):2244-52.

National Kidney Foundation. K/DOQI clinical practice guidelines for bone metabolism and disease in chronic kidney disease. Am J Kidney Dis 2003:42(Suppl3):S1-201.3

Negi S, Kita Y, Uchita K, Abe T. Ultrasonographic evaluation of shoulder joints in hemodialysis patients. Nippon Jinzo Gakkai Shi 1995;37(1):29-34.

Ohashi K. Pathogenesis of beta-2-microglobulin amyloidosis. Pathol Int 2001;51(1):110.

Schiffl H, Fischer R, Lang SM, Mangel E. Clinical manifestations of AB-amyloidosis: effects of biocompatibility. Nephrol Dial Transplant 2000;15:840-5.

Shin J, Nishioka M, Shinko S, Shibuya K, Sugiki M, Kasumoto H, i sur. Carpal tunnel syndrome and plasma beta2-microglobulin contcentration in hemodialysis patients. Ther Apher Dial 2008;12(1):62-6.

Sell DR, Monnier VM. End-stage renal disease and diabetes catalyze the formation of a pentose-derived crosslink from aging human collagen. J Clin Invest 1990;85(2):3804.

Sugiyama S, Miyata T, Inagi R, Kurokawa K. Implication of the glycoxidation and lipoxidation reactions in the pathogenesis of dialysis-related amyloidosis (Review). Int J Mol Med 1998;2(5):561-5.

Takahashi T, Kato A, Ikegaya N, Takita T, Maruyama Y, Hishida A, i sur. Ultrasound changes of the carpal tunnel in patients receiving long-term hemodialysis: a crosssectional and longitudinal study. Clin Nephrol 2002;57(3):230-6.

Tsvetkova S, Blagov B, Batalov A. Amyloid arthropathy in haemodialysis patientsradiological findings. Journal of IMAB-annual proceeding. (scientific papers) 2007; book 2: 46-48.

Zhang H, Liew CC, Marshall KW. Microarray analysis reveals the involvement of beta-2microglobulin (B2M) in human osteoarthritis. Osteoarthritis Cartilage 2002;10(12):950-60.

Wada T, Miyata T, Sakai H, Kurokawa K. Beta2-microglobulin and renal bone disease. Perit Dial Int 1999;19 Suppl 2:S413-6.

Warren DJ, Otieno LS. Carpal tunnel syndrome in patients on intermittent hemodialysis. Postgrad Med J 1975;51:450-2.

Weybright PN, Jacobson JA, Murry KH, Lin J, Fessell DP, Jamadar DA, i sur. Limited effectivness of sonography in revealing hip joint effusion: preliminary results in 21 adult patients with native and postoperative hips. AJR Am J Roentgenol 2003;181(1):215-8. 
Yamamoto S, Kazama JJ, Maruyama H, Nishi S, Narita I, Geyo F. Patients undergoing dialysis therapy for 30 years or more survive with serious osteoarticular disorders. Clin Nephrol 2008;70(6):496-502. 


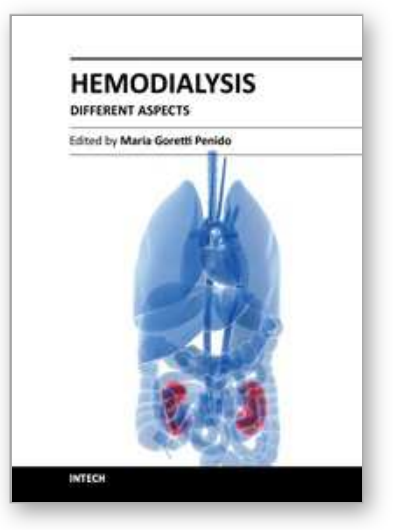

\author{
Hemodialysis - Different Aspects \\ Edited by Prof. Maria Goretti Penido
}

ISBN 978-953-307-315-6

Hard cover, 321 pages

Publisher InTech

Published online 14, November, 2011

Published in print edition November, 2011

The book provides practical and accessible information on all aspects of hemodialysis, with emphasis on dayto-day management of patients. It is quite comprehensive as it covers almost all the aspects of hemodialysis. In short it is a valuable book and an essential aid in the dialysis room.

\title{
How to reference
}

In order to correctly reference this scholarly work, feel free to copy and paste the following:

Damir Matoković, Miroslav Hašpl, Petar Petrić, Sanja Skorvaga, Vlado Drkulec and Goran Santak (2011). The Role of Ultrasonographic Monitoring for Hip Joint Changes in Patients with Chronic Renal Failure, Hemodialysis - Different Aspects, Prof. Maria Goretti Penido (Ed.), ISBN: 978-953-307-315-6, InTech, Available from: http://www.intechopen.com/books/hemodialysis-different-aspects/the-role-of-ultrasonographicmonitoring-for-hip-joint-changes-in-patients-with-chronic-renal-failure

\section{INTECH}

open science | open minds

\section{InTech Europe}

University Campus STeP Ri

Slavka Krautzeka 83/A

51000 Rijeka, Croatia

Phone: +385 (51) 770447

Fax: +385 (51) 686166

www.intechopen.com

\section{InTech China}

Unit 405, Office Block, Hotel Equatorial Shanghai

No.65, Yan An Road (West), Shanghai, 200040, China

中国上海市延安西路65号上海国际贵都大饭店办公楼 405 单元

Phone: +86-21-62489820

Fax: +86-21-62489821 
(C) 2011 The Author(s). Licensee IntechOpen. This is an open access article distributed under the terms of the Creative Commons Attribution 3.0 License, which permits unrestricted use, distribution, and reproduction in any medium, provided the original work is properly cited. 